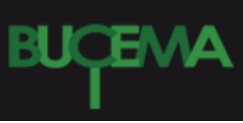

Bulletin du centre d'études médiévales d'Auxerre | BUCEMA

Hors-série $n^{\circ} 3 \mid 2010$

Présentation et mise en valeur des sites archéologiques religieux en milieu urbain

\title{
L'aménagement de sites archéologiques accessibles au public en contexte urbain : la politique adoptée par le canton de Genève
}

Jean Terrier

\section{OpenEdition}

\section{Journals}

Édition électronique

URL : https://journals.openedition.org/cem/11379

DOI : $10.4000 /$ cem. 11379

ISSN : 1954-3093

Éditeur

Centre d'études médiévales Saint-Germain d'Auxerre

Référence électronique

Jean Terrier, «L'aménagement de sites archéologiques accessibles au public en contexte urbain : la politique adoptée par le canton de Genève », Bulletin du centre d'études médiévales d'Auxerre | BUCEMA [En ligne], Hors-série $n^{\circ} 3$ | 2010, mis en ligne le 15 mars 2010, consulté le 03 mars 2023. URL : http:// journals.openedition.org/cem/11379; DOI : https://doi.org/10.4000/cem.11379

Ce document a été généré automatiquement le 3 mars 2023

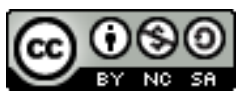

Creative Commons - Attribution - Pas d'Utilisation Commerciale - Partage dans les Mêmes Conditions 4.0 International - CC BY-NC-SA 4.0

https://creativecommons.org/licenses/by-nc-sa/4.0/ 


\title{
L'aménagement de sites archéologiques accessibles au public en contexte urbain : la politique adoptée par le canton de Genève
}

\author{
Jean Terrier
}

Le rôle du Service cantonal d'archéologie consiste à recenser, découvrir, étudier, sauvegarder et mettre en valeur le patrimoine archéologique conservé sur l'ensemble du territoire genevois. Afin de mettre en œuvre cette politique dans un contexte actuel qui n'est pas toujours acquis, il devient aujourd'hui primordial de développer une communication efficace auprès du public afin de convaincre les élus politiques de débloquer les fonds nécessaires à la prise en compte de cette dimension culturelle. La réalisation et l'aménagement de sites accessibles sont les piliers de cette sensibilisation, le succès de leur fréquentation étant leur corollaire indispensable. Au cours de ces quarante dernières années, plusieurs dossiers scientifiques ont été menés à Genève dans le contexte d'une approche systématique associant archéologies préventive et programmée qui ont abouti à la réalisation d'espaces archéologiques ouverts à la population. 


\section{Un site phare : la cathédrale Saint-Pierre}

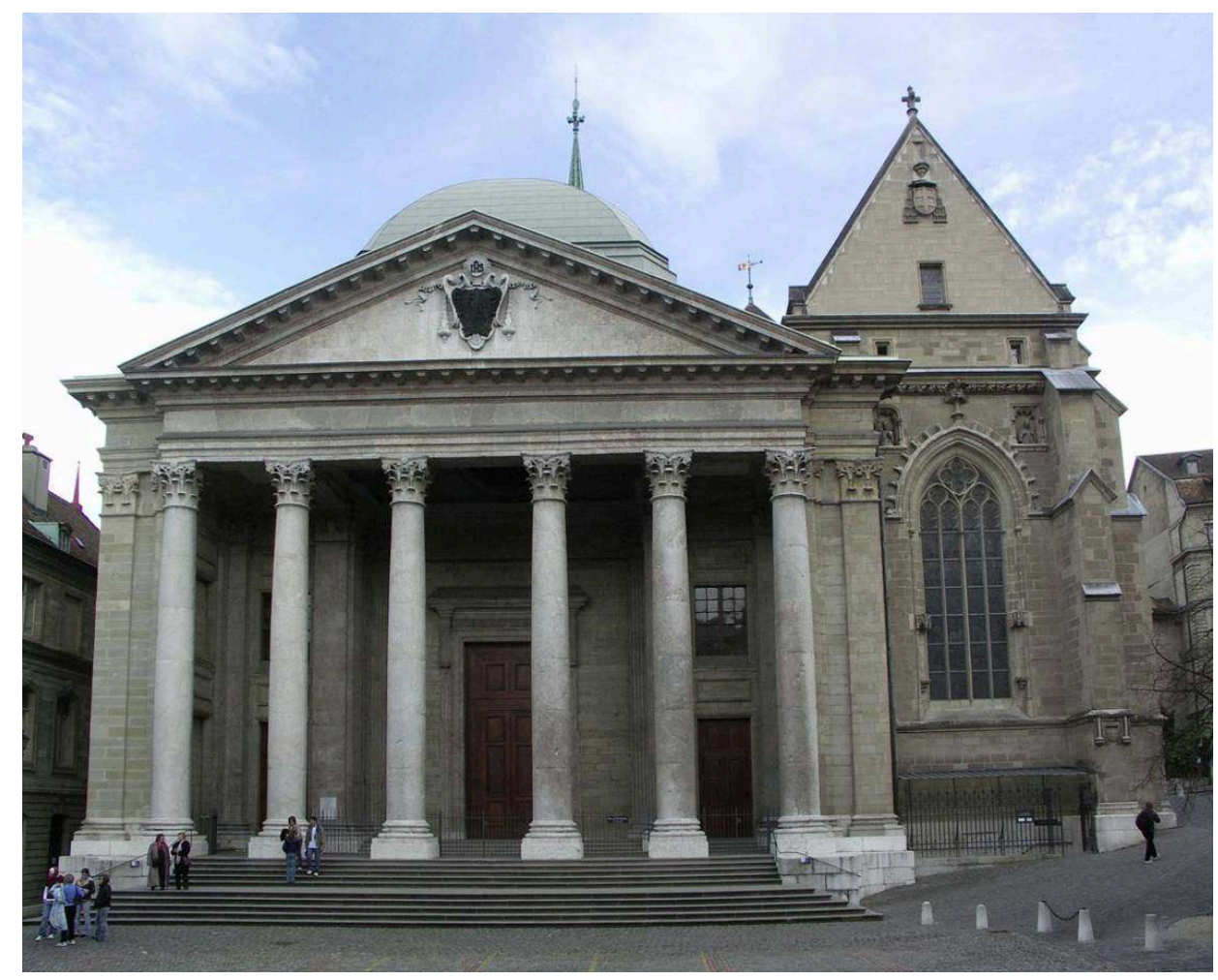

Fig. 1 - La cathédrale Saint-Pierre (cl. Marion Berti).

2 Les vestiges exceptionnels mis en valeur dans le sous-sol archéologique de la cathédrale Saint-Pierre permettent d'aborder la genèse de la cité de Genève. L'intérêt majeur de cet espace ouvert au public, outre la qualité de la présentation didactique ainsi que l'envergure des lieux, réside dans la conservation de vestiges illustrant l'impact de la christianisation sur l'urbanisation de la cité au cours de l'Antiquité tardive.

C'est à partir de la fin du IV ${ }^{\mathrm{e}}$ siècle, suite à la promulgation du christianisme en tant que religion d'Etat au sein de l'Empire romain, que la ville se dotera d'une parure monumentale impressionnante. Dès cette époque, ce ne sont pas moins de trois cathédrales avec des fonctions bien précises qui s'organiseront autour du baptistère, centre de la composition architecturale. Le pouvoir de l'évêque se manifestera aussi par l'édification d'un palais comprenant plusieurs salles de réception ainsi qu'une chapelle privée. Tous ces monuments seront sans cesse modifiés, transformés puis reconstruits pour satisfaire à l'évolution de la liturgie ou pour marquer le règne d'un nouveau prélat. Une telle complexité ne pouvait être abordée sur le plan archéologique qu'en poursuivant des investigations sur le long terme et en élargissant également le champ des découvertes au-delà de l'assiette de la cathédrale actuelle. 


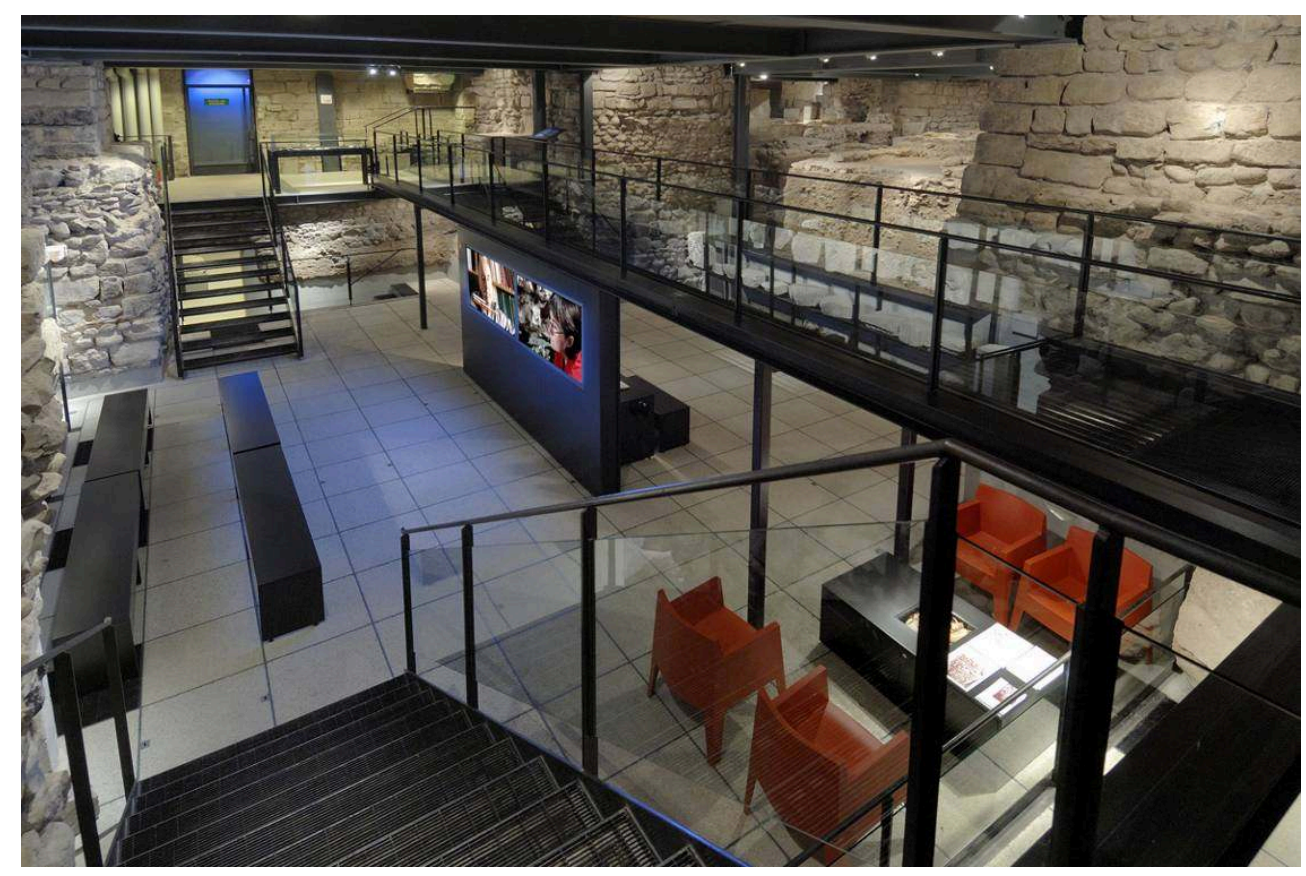

Fig. 2 - La cathédrale Saint-Pierre (cl. Alain Germond).

4 Cette riche et longue évolution peut être perçue lors de la visite du site archéologique aménagé sous la cathédrale dans un cadre résolument contemporain et à l'aide d'un appareil didactique judicieusement disposé le long du parcours. La réalisation de ce véritable musée de site a été honorée en 2008 par l'attribution d'une « Médaille Europa Nostra » dans le cadre du Prix du patrimoine culturel de l'Union européenne rendant hommage à un projet exemplaire dans un pays, la Suisse, qui ne fait pourtant pas partie de cette instance politique. Si cette réalisation unique joue le rôle de véritable vitrine pour l'archéologie genevoise, et cela bien au-delà des frontières, elle constitue surtout un cadre de référence précieux à partir duquel peut s'articuler une véritable politique de l'archéologie au sein du territoire cantonal.

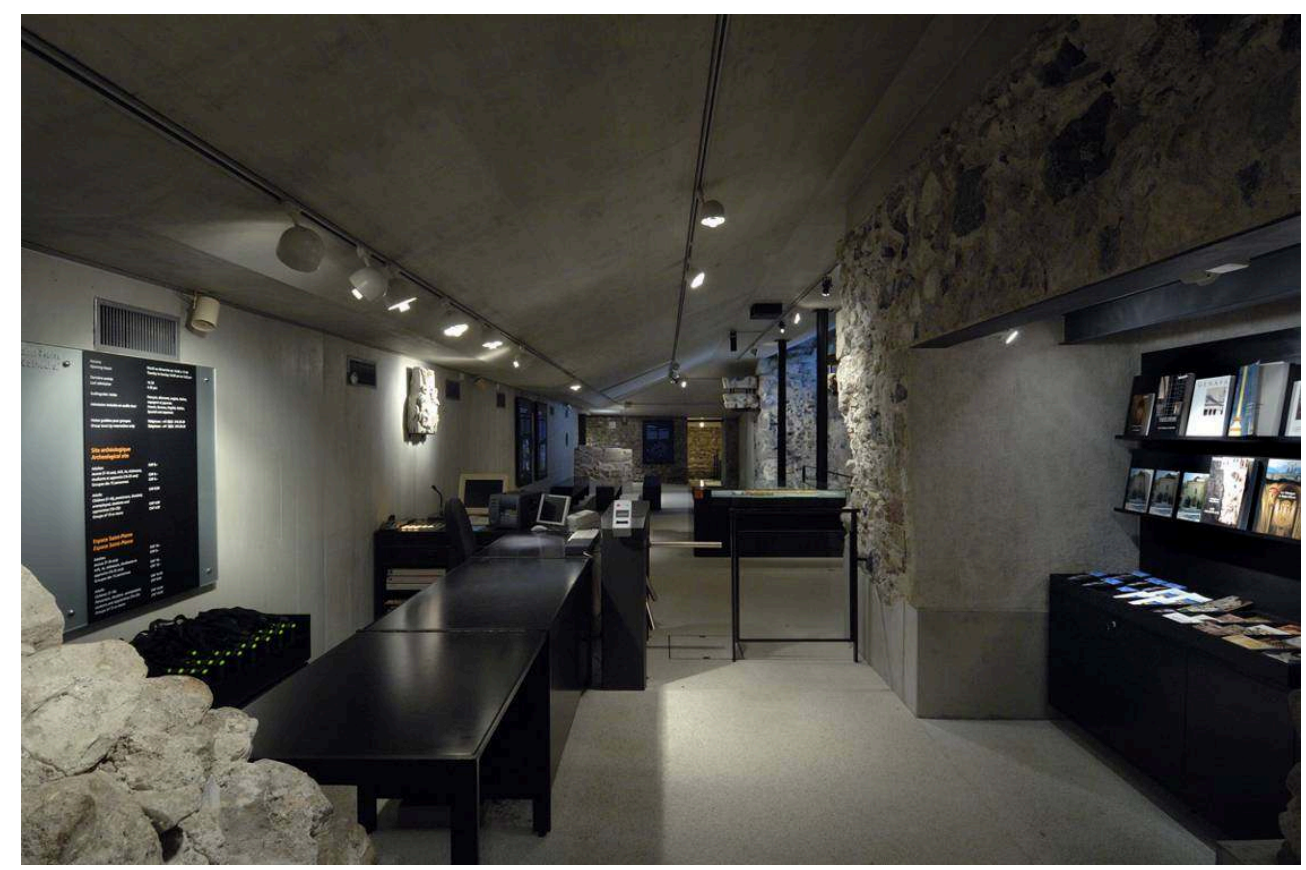

Fig. 3 - Cathédrale, aménagements (cl. Alain Germond). 


\section{Les autres sites}

Plusieurs espaces archéologiques accessibles au public illustrent également certaines pages de l'histoire de la cité par l'intermédiaire de vestiges particulièrement intéressants présentés dans des cadres sensiblement différents. Le nouveau site aménagé en partie sous l'église médiévale de Saint-Gervais met en lumière l'histoire d'un important faubourg de la ville. La présentation du sous-sol de l'église de La Madeleine, localisée en contrebas de la cathédrale, illustre les origines de cet édifice qui sont liées à l'établissement d'un cimetière antique. Dans un tout autre contexte, le parking souterrain de Saint-Antoine intègre un immense pan des fortifications bastionnées $\mathrm{du} \mathrm{xVI}^{\mathrm{e}}$ siècle. Des promenades archéologiques sont également proposées aux visiteurs en périphérie du noyau urbain. Ainsi, les ruines de l'ancien prieuré médiéval de Saint-Jean-hors-les-murs sont accessibles au sein d'un parc public. C'est aussi le cas d'une somptueuse demeure antique étudiée pendant plusieurs années à l'intérieur du parc de La Grange dont les vestiges sont présentés dans le cadre d'un concept paysager contemporain.

\section{L'église Saint-Gervais}

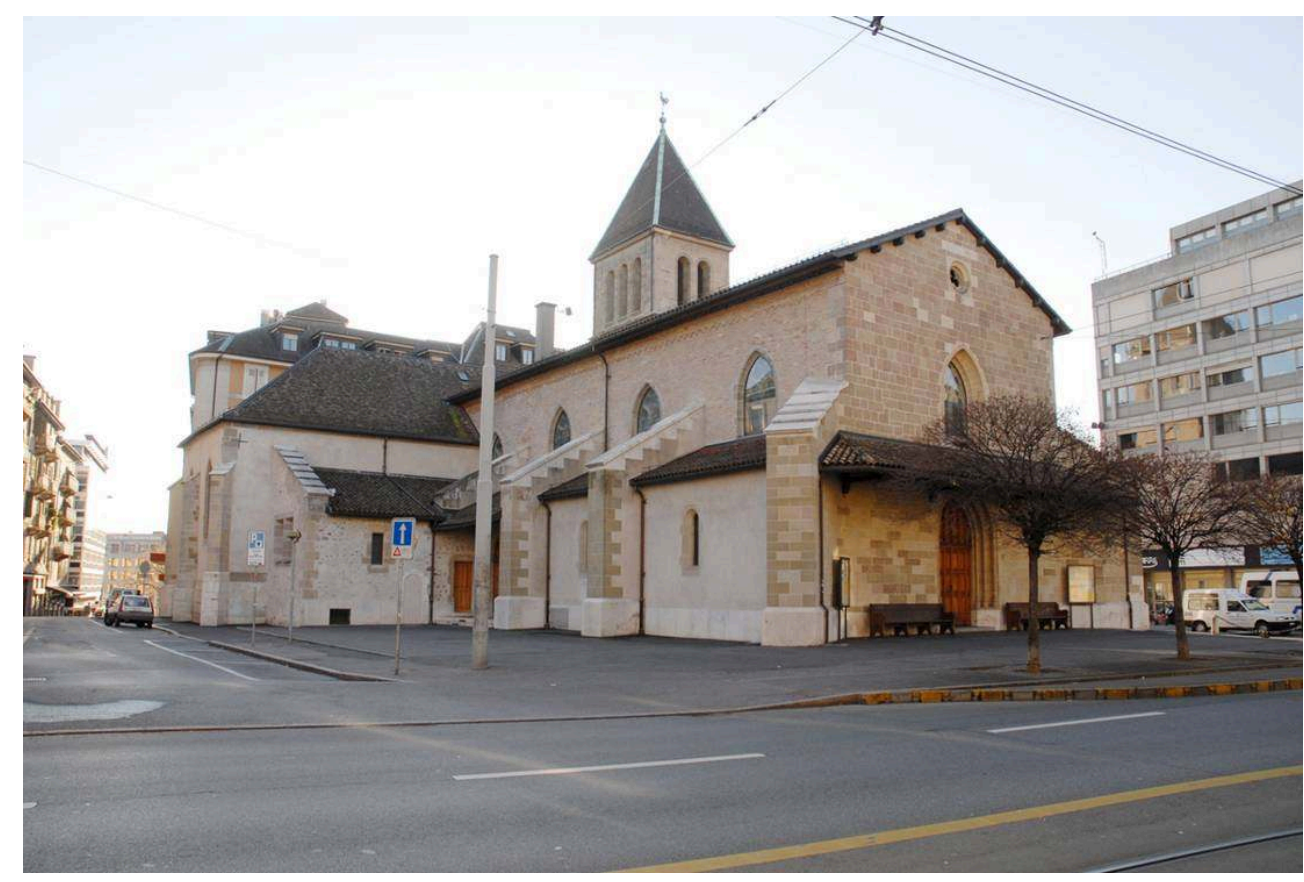

Fig. 4 - L'église Saint-Gervais (cl. M. Berti).

6 Un parcours archéologique à travers les vestiges retraçant les différentes occupations du site est en cours de réalisation dans le sous-sol de ce monument historique. Le promeneur pourra ainsi remonter le temps à la découverte d'un des quartiers les plus anciens de Genève. Auparavant, il aura eu la possibilité d'effectuer la visite de l'église actuelle datée de la première moitié $d u \mathrm{xv}^{\mathrm{e}}$ siècle, visite agrémentée de panneaux explicatifs.

Les recherches archéologiques effectuées dans ce contexte ont mis au jour les traces de l'établissement humain le plus ancien reconnu sur le territoire du canton de Genève; il 
s'agit d'un habitat du Néolithique daté vers 4000 avant J.-C. Une tombe à incinération du Bronze final, témoin d'une aire d'inhumation plus récente, a également été retrouvée à cet endroit.

8 Le premier témoignage attestant la présence d'un lieu de culte consiste en un alignement de pierres dressées établi le long d'une voie. La datation de cet ensemble est délicate à préciser. La voie fut déplacée entre 60 et 40 avant J.-C. Deux mégalithes furent alors couchés afin de procéder à un nivellement de la zone pour permettre l'édification d'un bâtiment en bois vers 40 avant J.-C. Ce bâtiment sera bientôt remplacé par d'autres constructions en terre et en bois vouées au culte et à l'habitat. C'est durant la première moitié du Ier siècle de notre ère que l'on bâtit un imposant sanctuaire gallo-romain en brique crue et en pierre dont l'architecture et l'organisation des espaces sacrés seront modifiés au fil des siècles. Cet ensemble religieux fut délaissé au $\mathrm{IV}^{\mathrm{e}}$ siècle suite à un incendie.

9 Un mausolée sera bientôt installé à proximité immédiate de la voie. Ce monument est sans doute à l'origine de la vaste église funéraire au plan en forme de croix qui sera édifiée au v viècle. Un caveau semi-hypogé était aménagé sous le chœur de cet édifice chrétien et son accès est aujourd'hui remis en valeur dans l'église actuelle.

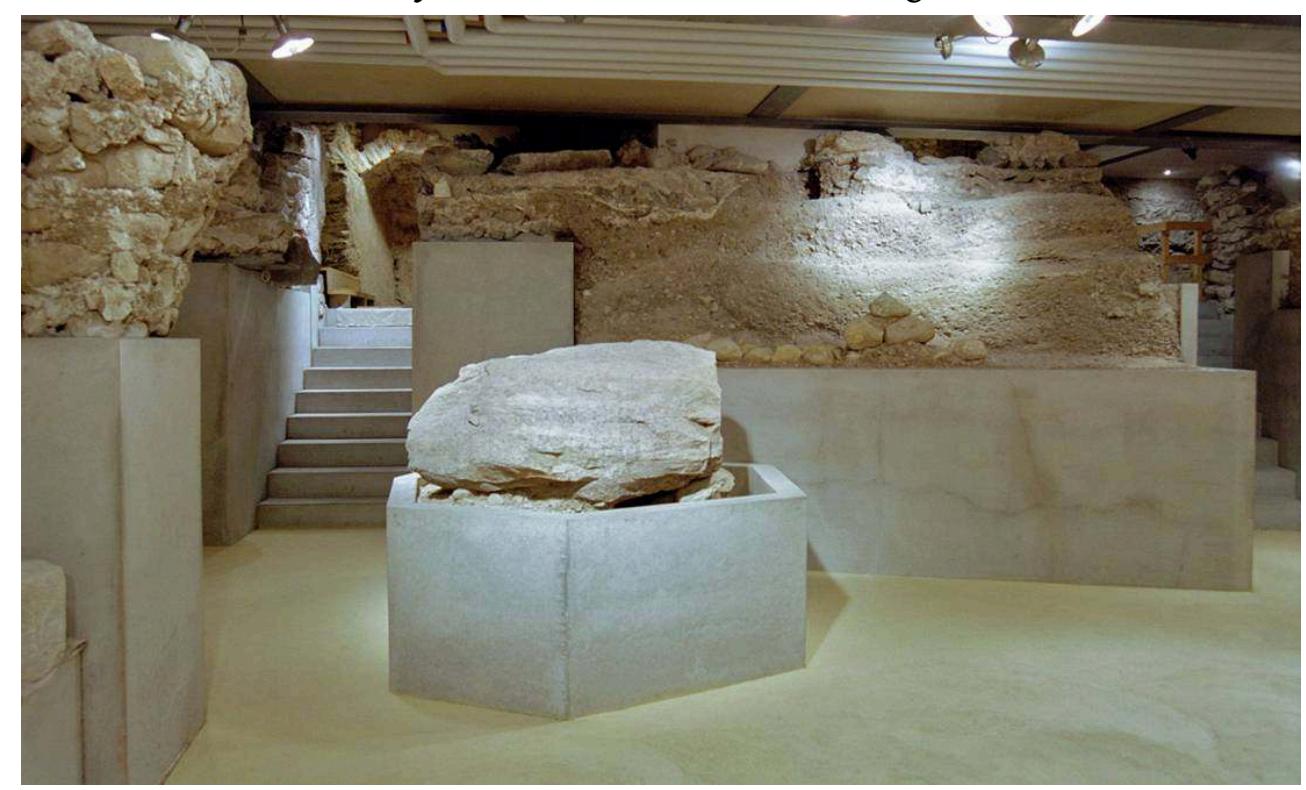

Fig. 5 et 6 : Aménagement du site archéologique (cl. M. Berti). 


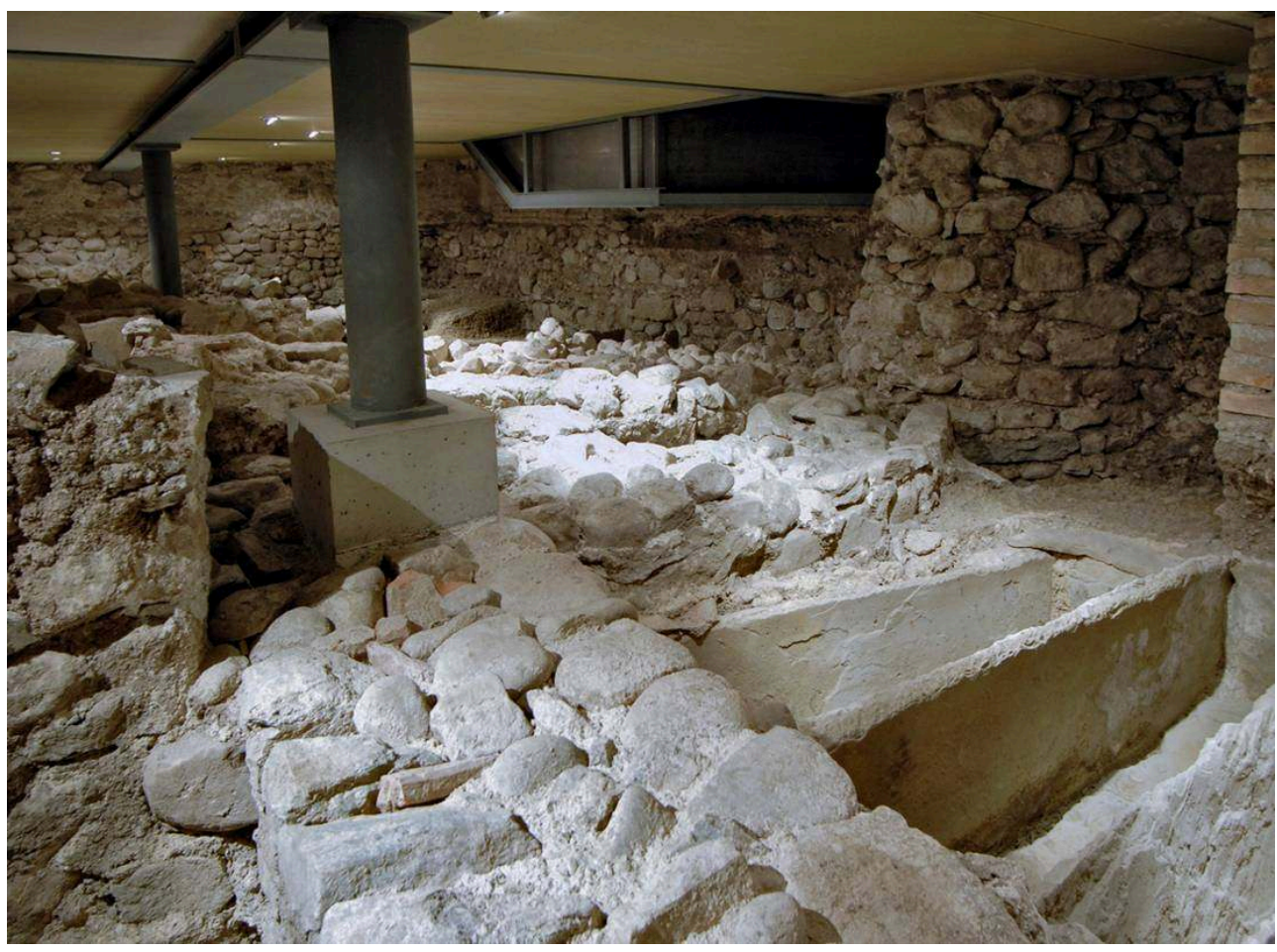

\section{L'église de La Madeleine}

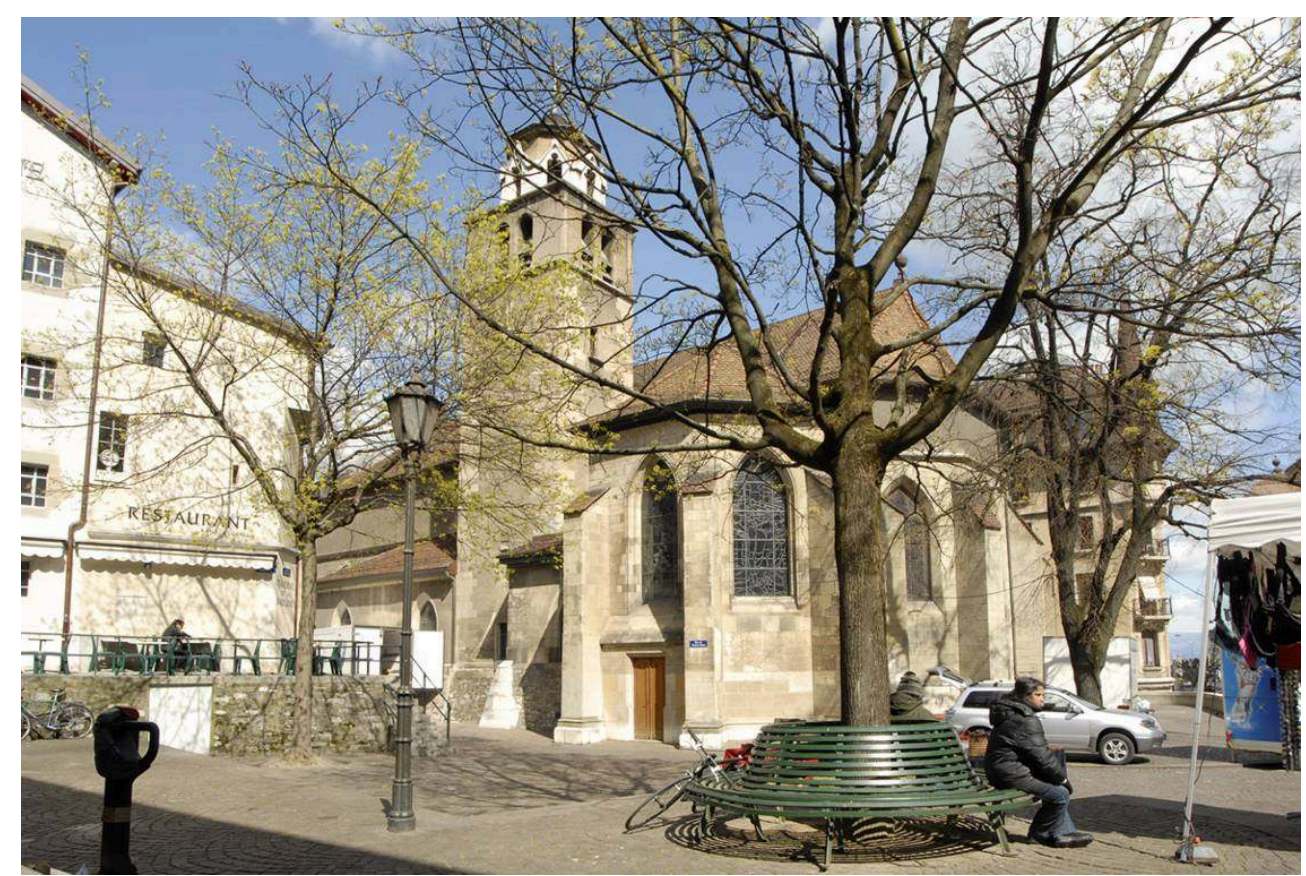

Fig. 7 - L'église de La Madeleine (cl. M. Berti).

10 Le site accessible dans le sous-sol de l'église de la Madeleine correspond à un aménagement temporaire au sein duquel les visiteurs peuvent aujourd'hui découvrir la riche histoire de cette partie de la ville proche des rives du lac grâce à l'aménagement d'un cheminement en bois. 
11 L'église de la Madeleine a été édifiée sur l'emplacement d'un ancien quartier portuaire dont les origines remontent au dernier quart $\mathrm{du} \mathrm{II}^{\mathrm{e}}$ siècle avant J.-C. Une résidence sera construite sur cette zone durant l'époque romaine. À partir de la fin du $\mathrm{III}^{\mathrm{e}}$ siècle et suite à une période de trouble, l'étendue de la cité sera réduite au sommet de la colline par la réalisation d'une enceinte fortifiée. Ce quartier semble alors ruiné et une aire funéraire se développera sur ce secteur localisé désormais à l'extérieur de la ville enfermée dans ses murs. Ce cimetière est bientôt entouré d'une clôture contre laquelle est adossé un petit oratoire abritant une tombe vénérée ou de précieuses reliques

C'est au $\mathrm{V}^{\mathrm{e}}-\mathrm{VI}^{\mathrm{e}}$ siècle qu'une première église funéraire est édifiée en ce lieu. Elle est ensuite en partie modifiée pour réaliser un édifice de plus grande dimension tout en prenant soin de maintenir le petit oratoire en tant que chapelle. Au cours des temps carolingiens, l'église est entièrement reconstruite avec une taille réduite. Dès cette époque, la présence de fonts baptismaux semble attester la naissance d'une communauté de fidèles préfigurant ainsi la paroisse médiévale de la Madeleine. Au cours $\mathrm{du} \mathrm{XI}$ siècle, une nouvelle église est bâtie, dotée du traditionnel chœur carré caractéristique de nos régions. Elle laissera ensuite place à l'église actuelle dont la construction remonte au $\mathrm{Xv}^{\mathrm{e}}$ siècle.

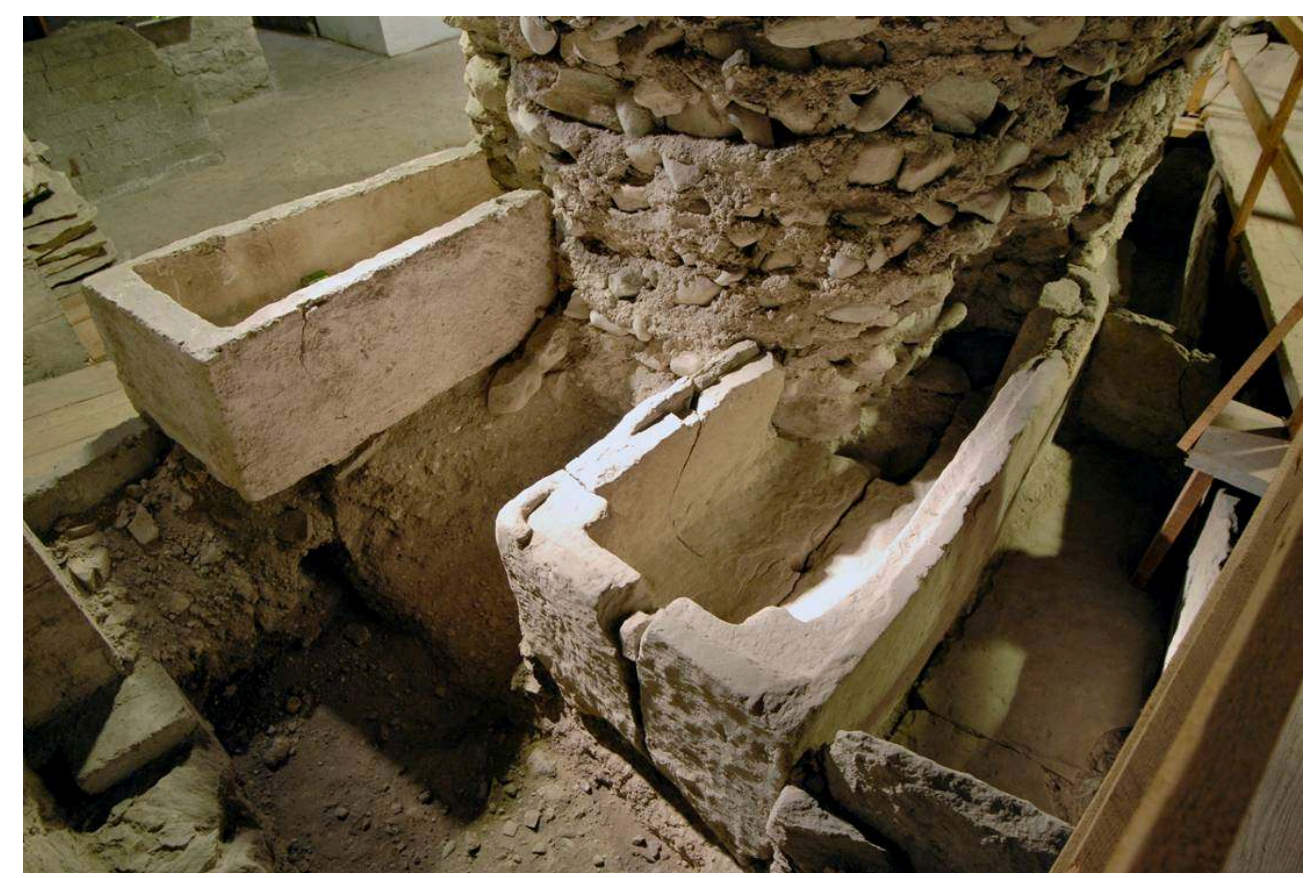

Fig. 8 et 9 - Site archéologique (cl. M. Berti). 


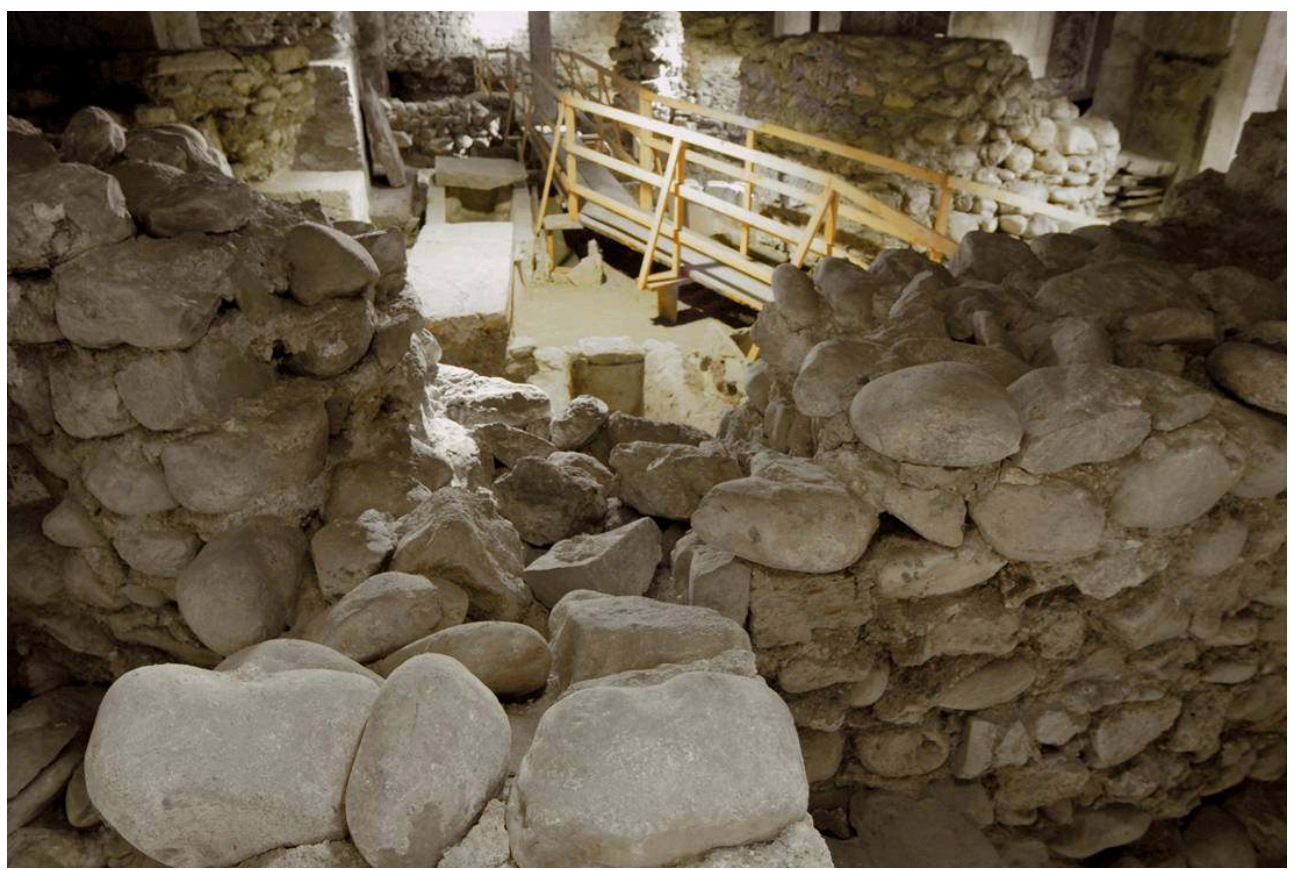

\section{Le Parking Saint-Antoine}

Lors des terrassements effectués pour la réalisation du parking souterrain de SaintAntoine, un vaste tronçon des fortifications protégeant la ville au XvI siècle fut mis au jour. Suite à cette importante découverte et au vu de la qualité des vestiges dégagés, il fut décidé non seulement de conserver ces gigantesques murailles, mais également de les mettre en valeur afin de permettre à un large public d'accéder ainsi à une page importante de l'histoire genevoise. Aujourd'hui, des panneaux et une maquette renseignent le visiteur sur l'évolution des fortifications de la cité, depuis la première enceinte du Bas-Empire jusqu'au démantèlement de l'ultime couronne bastionnée intervenu au milieu du XIX ${ }^{e}$ siècle. 


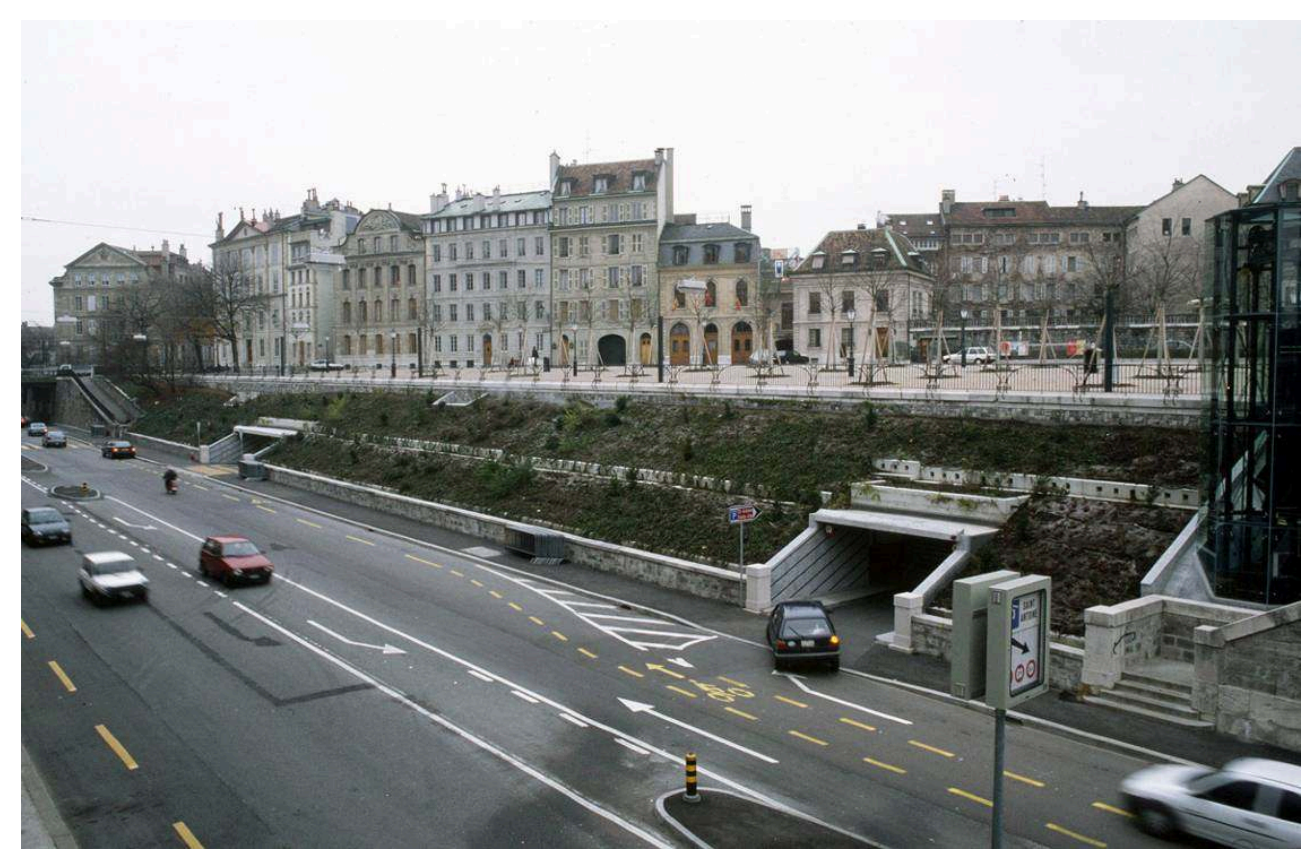

Fig. 10 - Parking Saint-Antoine, vue des fortifications (cl. J.-B. Sevette).

14 La courtine visible dans le parking reliait le bastion du Pin à celui de Saint-Antoine. La maçonnerie, d'une épaisseur de 2,20 mètres, est constituée principalement de petits boulets mêlés par endroits à des blocs récupérés sur des édifices détruits lors de ce vaste chantier de fortification. Aucun élément architectural ne vient rompre la monotonie de l'ouvrage, hormis une poterne au sud qui aboutissait aux fossés situés au pied de la muraille. Le flanc droit du bastion conservé dans le site archéologique correspond à celui de Saint-Antoine, construit en 1560. Une galerie assurait la circulation à l'intérieur du bastion; le long de son flanc, elle comportait de larges niches dans lesquelles pouvait se positionner l'infanterie alors que des chambres de tir abritaient les pièces d'artillerie de gros calibre. Des embrasures percées à la base des murs permettaient d'effectuer des tirs rasants dans le fond des fossés aménagés audevant des fortifications. Un tel dispositif empêchait toute tentative d'approche de la part de l'ennemi. 


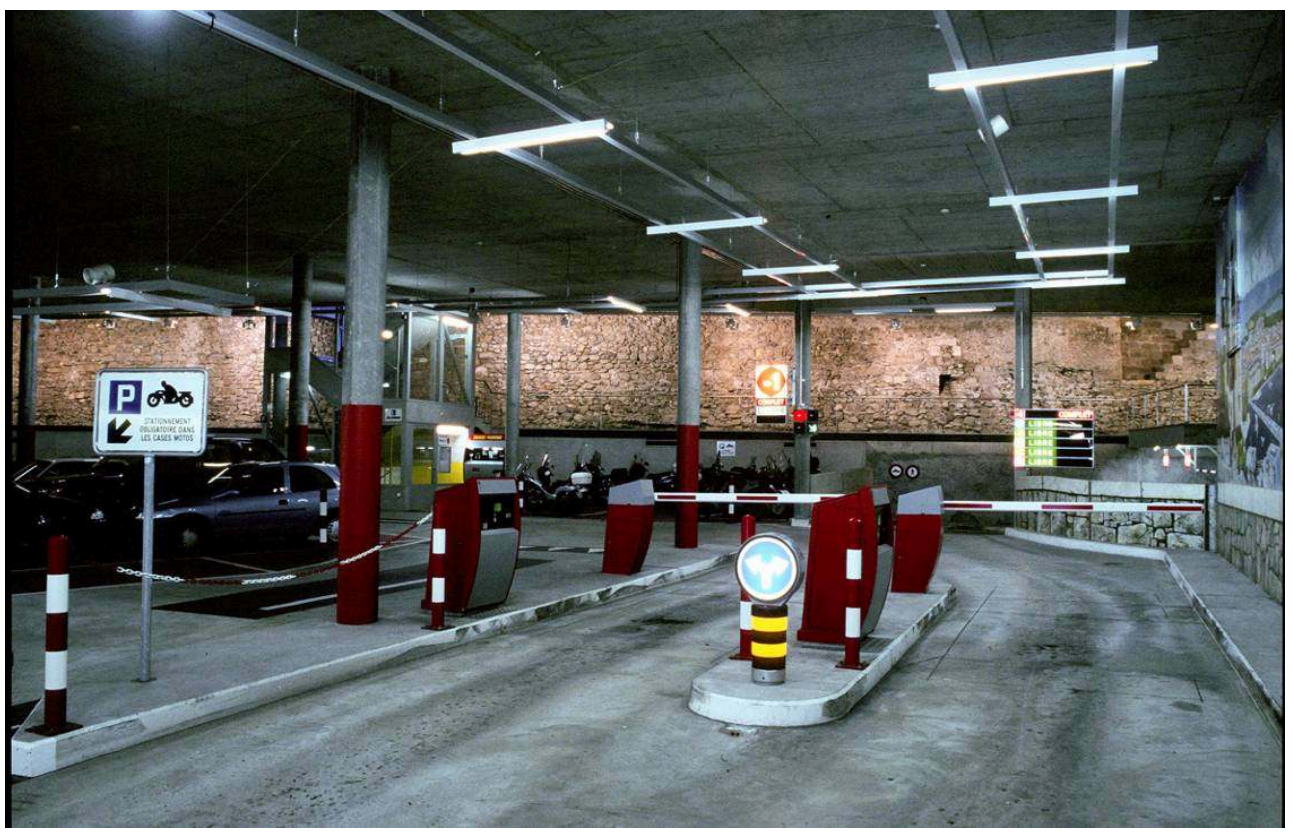

Fig. 11 - Site aménagé dans le parking souterrain (cl. J.-B. Sevette).

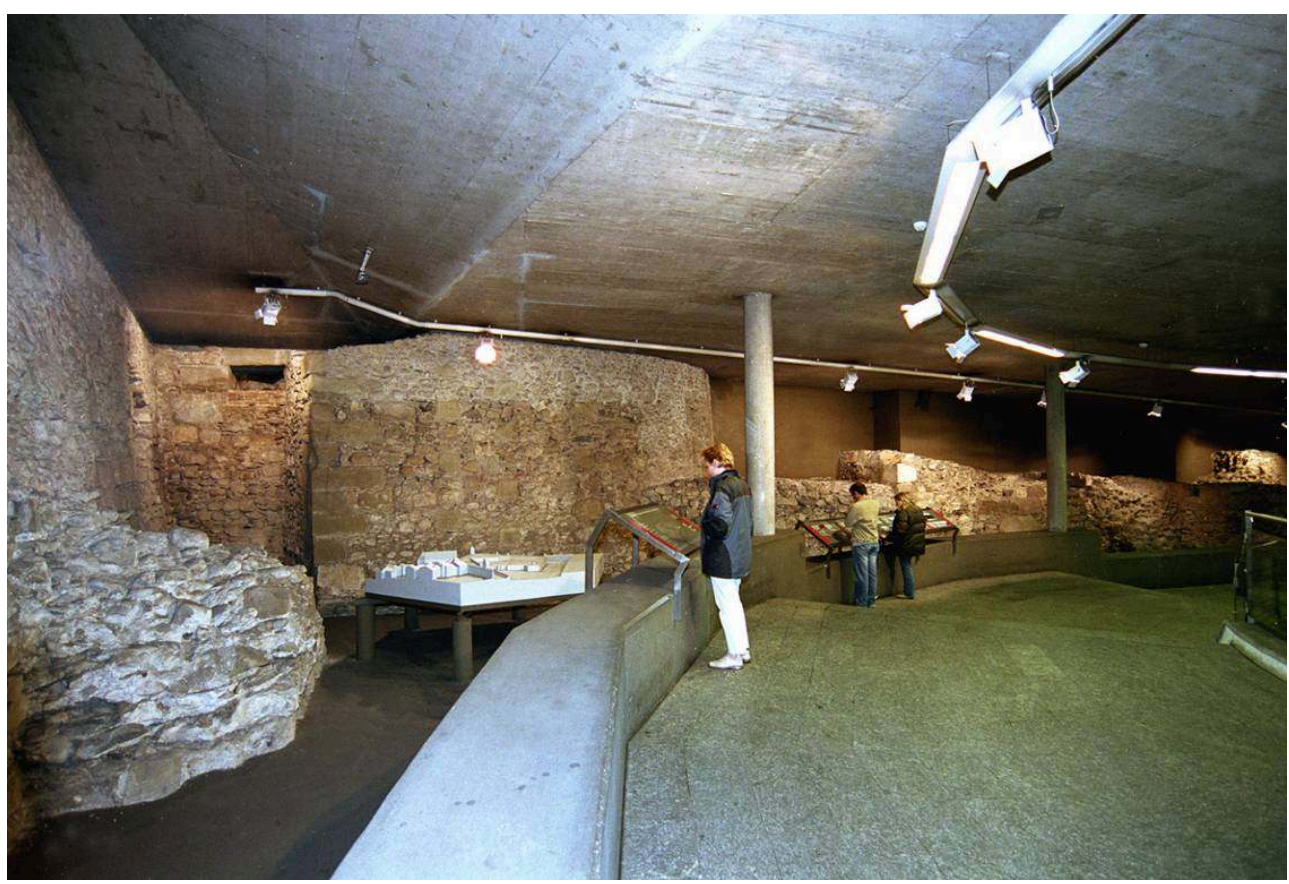

Fig. 12 - Site aménagé dans le parking souterrain (cl. J.-B. Sevette).

\section{L'ancien prieuré Saint-Jean-hors-les-Murs}

15 Une promenade archéologique a été aménagée en 1973 afin de valoriser les vestiges du monastère de Saint-Jean-hors-les-murs découverts en 1966. Placé dans un quartier aujourd'hui fortement urbanisé qui est confronté à de lourdes nuisances liées à la densité du trafic motorisé, cet aménagement constitue un véritable îlot de verdure au sein de la ville invitant le promeneur à venir flâner dans les ruines de l'église romane et de son cloître. 


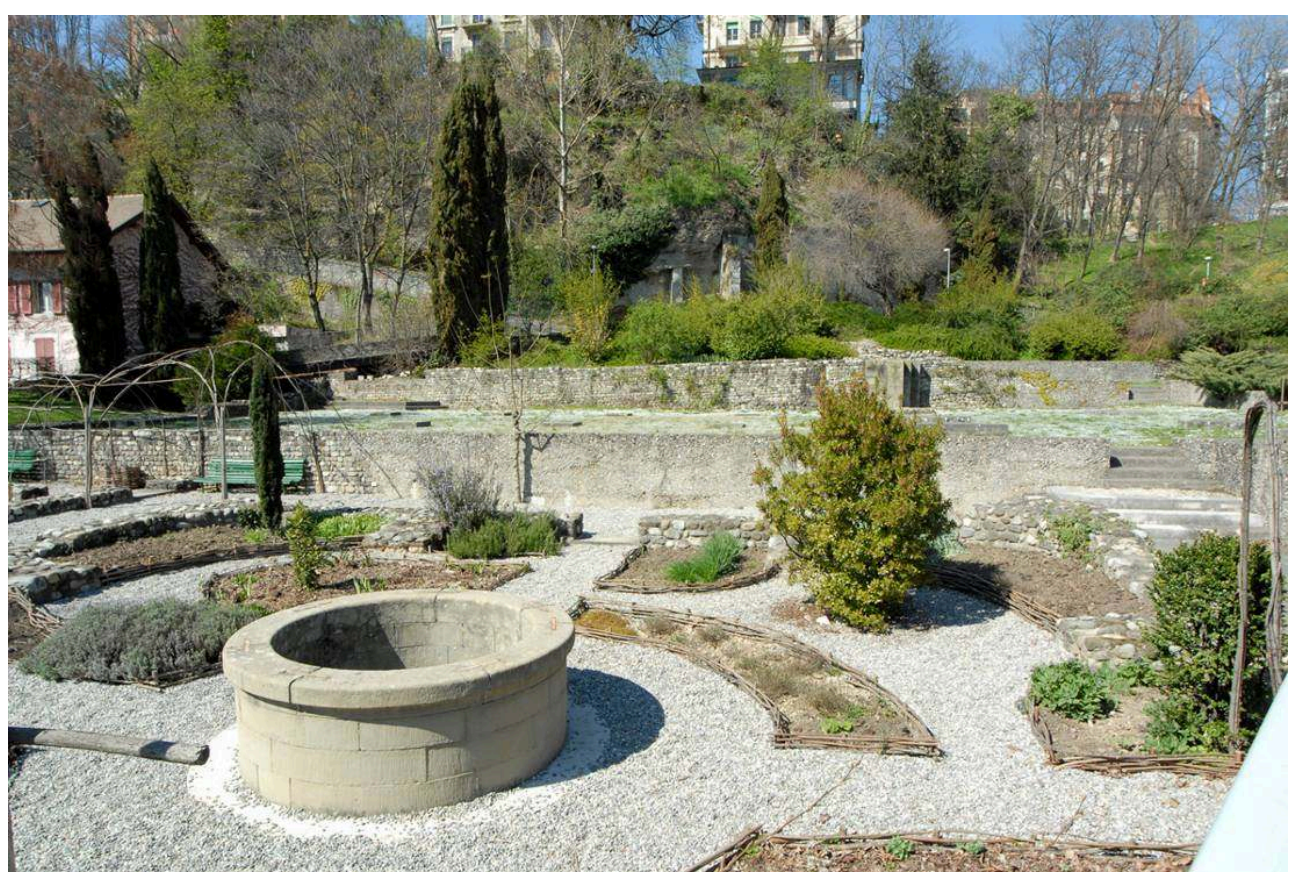

Fig. 13 et 14 - La promenade archéologique (cl. M. Berti).

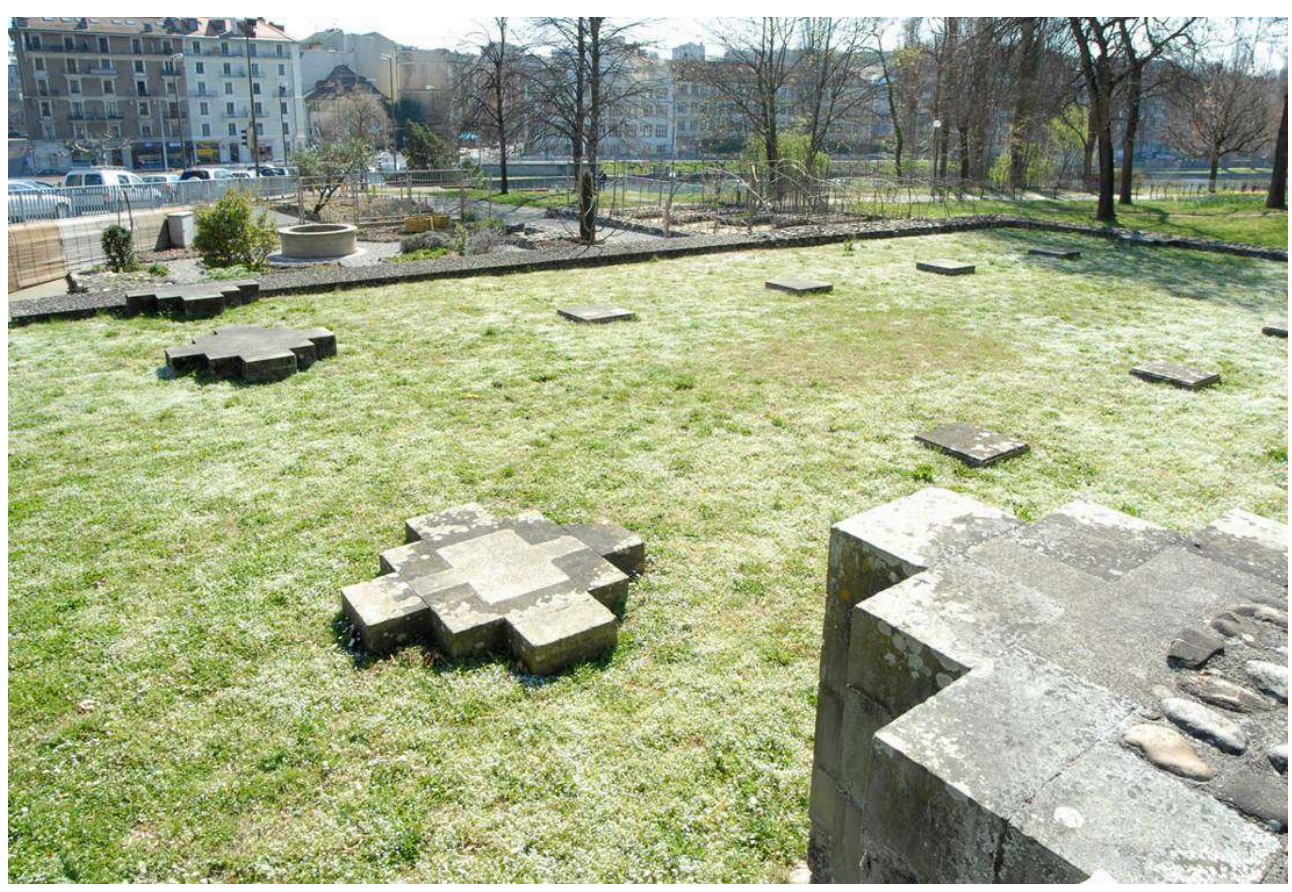

16 Les origines du site sont anciennes puisqu'une église en bois avait déjà été édifiée en cet endroit au VIII ${ }^{\mathrm{e}}-\mathrm{IX}^{\mathrm{e}}$ siècle. En fait, ce lieu était tout désigné pour accueillir un sanctuaire chrétien, un récit de la Vie des Pères du Jura relatant la guérison de deux lépreux par saint Romain dans une grotte que l'historiographie traditionnelle situe à proximité. L'édifice religieux perpétuait peut-être la mémoire de ce miracle. Aux environs de l'an mil, une basilique en pierre de près de 32 mètres de longueur, dotée de plusieurs annexes conventuelles, succède à l'église en bois. Elle est remplacée au $\mathrm{XII}^{\mathrm{e}}$ siècle par une église romane érigée en prieuré. Le monastère est ensuite abandonné lors des événements liés à la Réforme protestante, pour être finalement démantelé, les 
matériaux provenant de sa démolition étant principalement utilisés pour l'édification des nouvelles fortifications bastionnées.

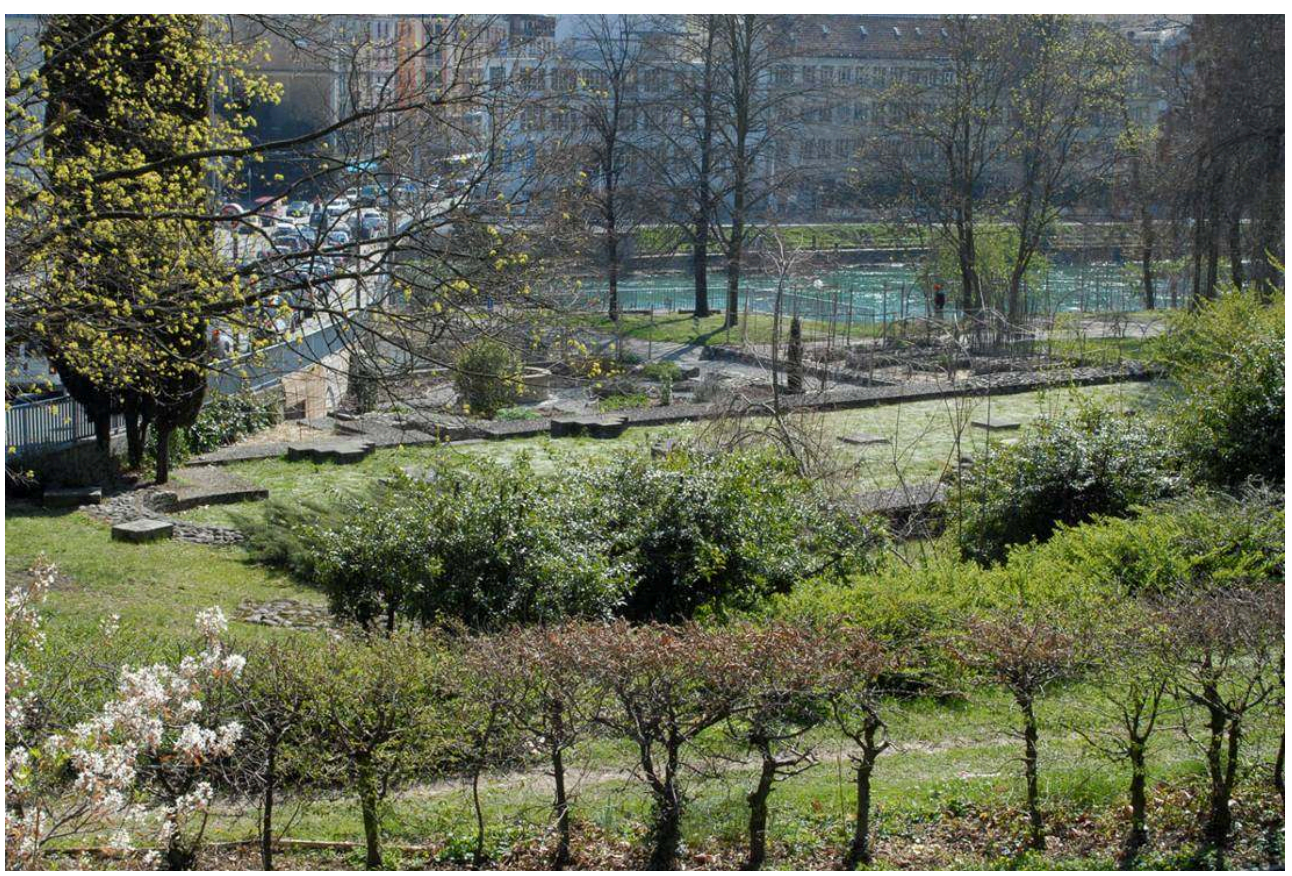

Fig. 15 - La promenade archéologique (cl. M. Berti)

\section{Le Parc de La Grange}

17 Siège d'une fouille de grande envergure menée sur plusieurs années, le Parc de La Grange est aujourd'hui considéré à Genève comme une véritable réserve archéologique. La mise en valeur des découvertes effectuées, notamment les vestiges de mégalithes préhistoriques et d'une villa gallo-romaine, est réalisée dans le cadre d'un concept d'architecture paysagère alliant le métal, le minéral et le végétal. Aux trois entrées principales du parc, des panneaux informatifs complets orientent le visiteur en l'incitant à se diriger vers le lieu des découvertes. Sur place, quatre tables d'orientation, positionnées aux quatre points cardinaux de l'établissement antique, fournissent des explications sur les principales occupations du site. 


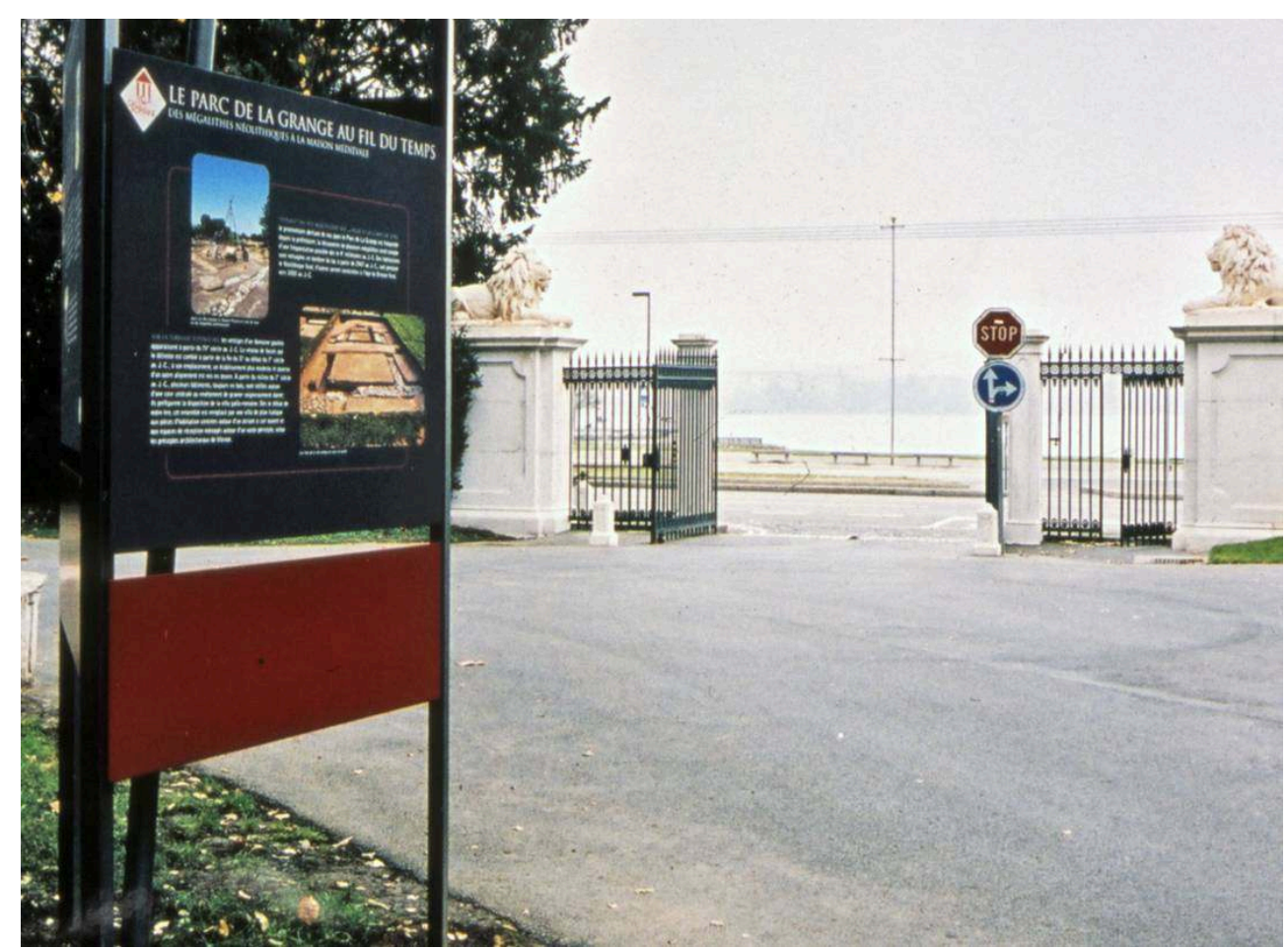

Fig. 16 - Promenade archéologique (cl. M. Delley).

Dans la partie inférieure du Parc de La Grange, un établissement de l'âge du Bronze final a été mis en évidence en bordure de la berge préhistorique du lac, alors qu'en amont, sous l'emprise de la villa romaine, les restes d'un regroupement mégalithique, érigé probablement entre le Néolithique et l'âge du Bronze, a pu être reconnu. C'est sur cette zone et à partir du $\mathrm{II}^{\mathrm{e}}$ siècle avant J.-C. qu'apparaissent les premières traces liées à un établissement allobroge de grande importance. Subissant plusieurs transformations, cet ensemble sera remplacé au début du Ier siècle de notre ère par une imposante villa à atrium et péristyle. Cette nouvelle réalisation architecturale constitue un véritable palais d'inspiration italique exprimant bien la volonté de son propriétaire, sans doute un membre d'une grande famille aristocratique allobroge, de se référer à la culture romaine tout en étalant sa puissance.

Dans le courant du II ${ }^{e}$ siècle après J.-C., ce vaste édifice sera agrandi sur son flanc ouest par l'adjonction d'un bâtiment quadrangulaire qui se développera par la suite pour être finalement doté d'une abside dans le courant $\mathrm{du} \mathrm{IV}^{\mathrm{e}}$ siècle. L'ensemble restera vraisemblablement en usage jusqu'au ve siècle. Au-delà de cette période, il semble que seule la partie occidentale soit maintenue; elle sera encore augmentée de petites constructions annexes réalisées entre le ve et le $\mathrm{vl}^{\mathrm{e}}$ siècle. Une importante bâtisse en bois identifiée par une série d'alignement de trous de poteau reprendra le plan de l'édifice précédent à l'aube du Moyen Âge, cette construction demeurera probablement en fonction jusqu'au XIv ${ }^{e}$ siècle. 


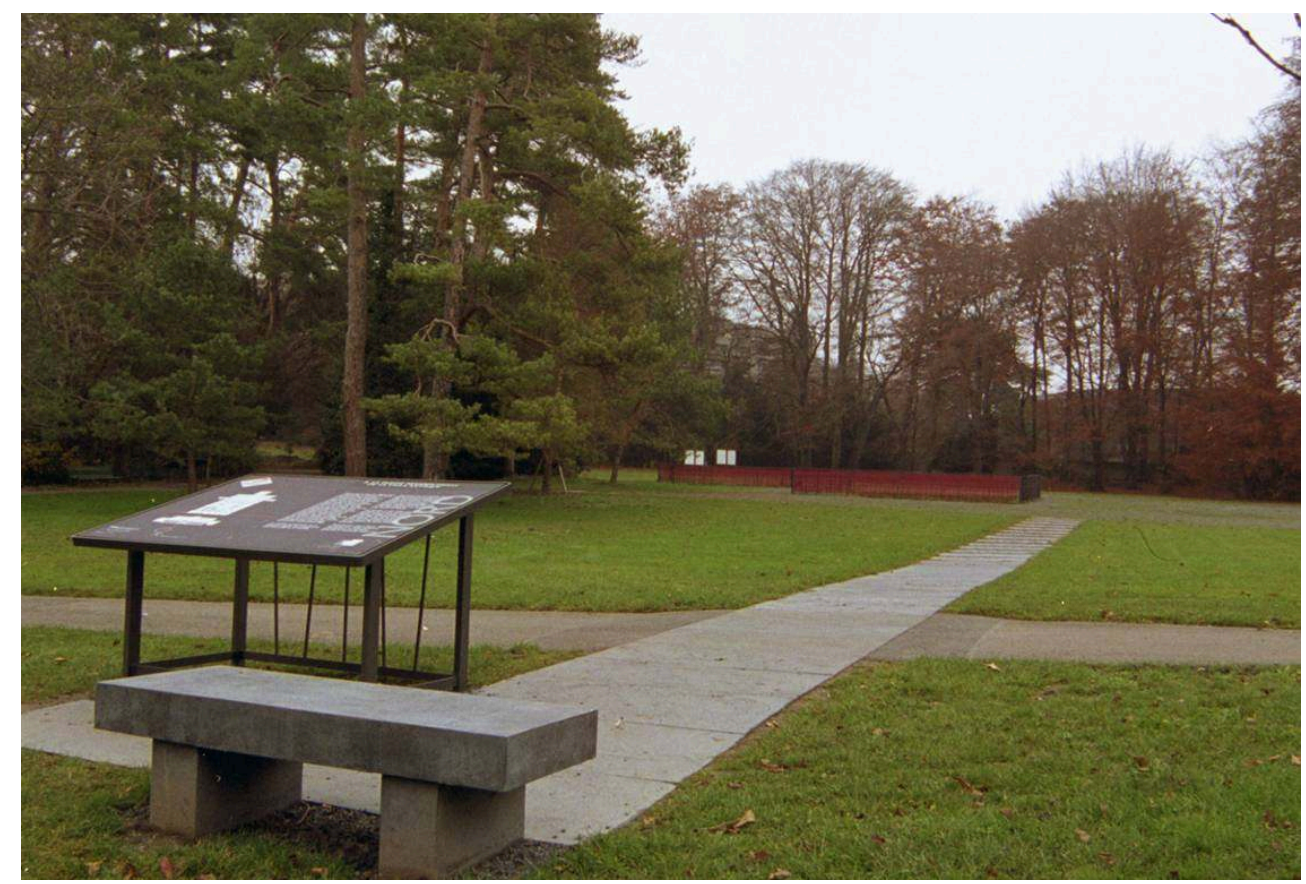

Fig. 17 et 18 - Promenade archéologique (cl. M. Delley).

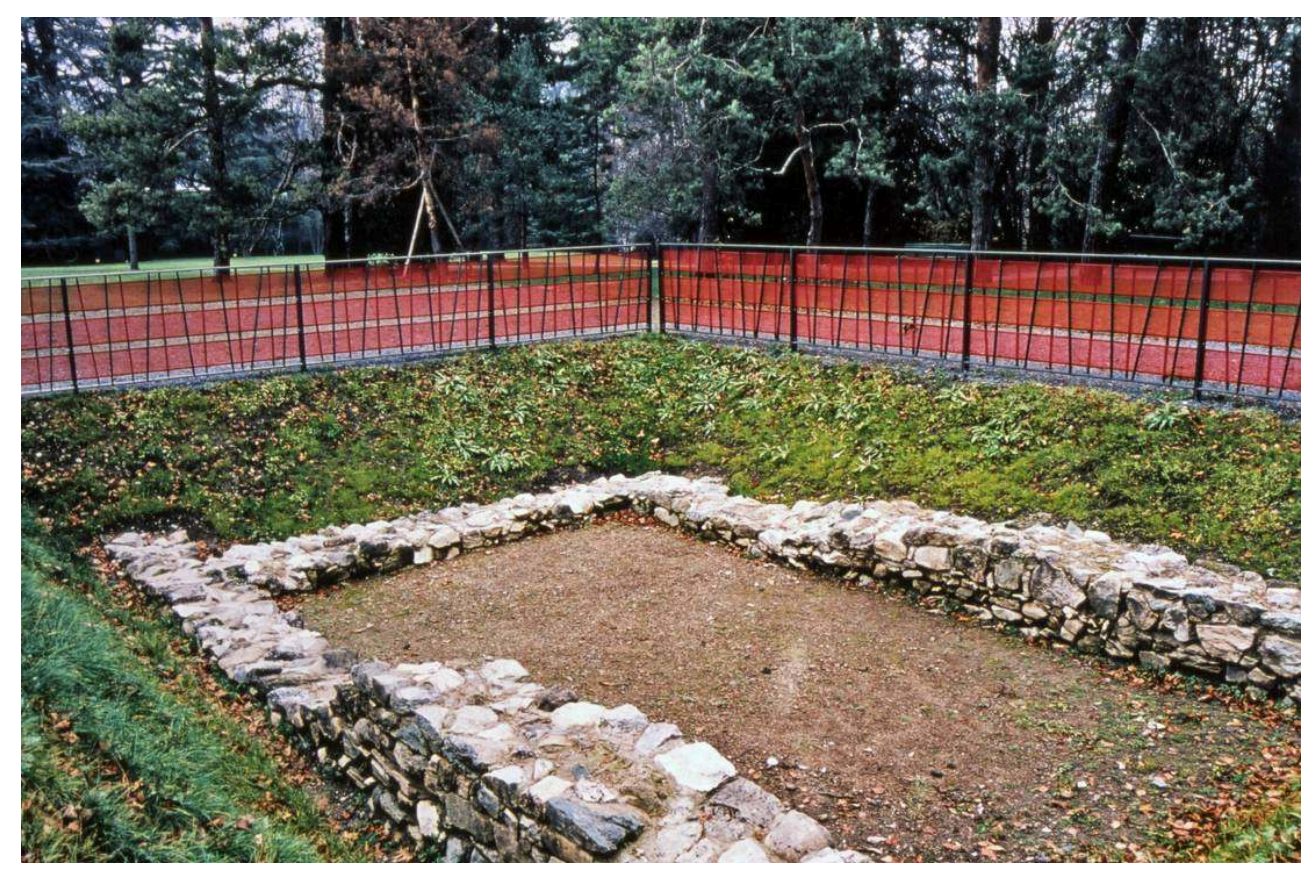

\section{Une archéologie pour l'avenir}

20 La mise en valeur des découvertes archéologiques et leur diffusion auprès d'un large public constituent une mission primordiale du Service cantonal d'archéologie qui se doit de porter ses activités à la connaissance du plus grand nombre et inciter ainsi à la protection d'un patrimoine unique et fragile. Afin de faciliter les contacts avec la population, un site internet (www.geneve.ch/patrimoine/sca) a été réalisé pour présenter l'actualité archéologique genevoise ainsi que les possibilités de visites offertes à tous. De plus, afin d'établir un véritable dialogue entre ces différents 
aménagements de sites et les riches collections d'objets archéologiques, un projet de réalisation de salles d'archéologie régionale au sein du Musée d'art et d'histoire de la ville situé aux portes de la cité médiévale est en cours. C'est donc au prix de tous ces efforts didactiques que la pérennité de l'archéologie pourra être assurée et, par la même, la reconnaissance de sa valeur patrimoniale auprès des générations futures.

\section{BIBLIOGRAPHIE}

Orientation bibliographique

BONNET, Ch., « Les premiers édifices chrétiens de la Madeleine à Genève, Étude archéologique et recherches sur les fonctions funéraires ", dans Mémoires et documents publiés par la Société d'histoire et d'archéologie de Genève, t. VIII, Genève, 1977.

BONNET, Ch., « Aménagement des sites archéologiques : les exemples d'Aoste, de Grenoble et de Genève », dans Collection Patrimoine architectural, 22, Strasbourg, 1992, p. 3-9.

BONNET, Ch., «Les fouilles de l'ancien groupe épiscopal de Genève », dans Cahiers d'archéologie genevoise, t. I, Genève, 1993.

BONNET, Ch., «Lieux de mémoire ou l'archéologie demain », dans Genava, n.s., XLII, Genève, 1994, p. 19-20.

BONNET, Ch., « Un service cantonal d'archéologie : pourquoi ?, dans Patrimoine et architecture, cahier n 3, Genève, 1997, p. 46-47.

BONNET, Ch., «L'expérience genevoise, 30 ans d'archéologie médiévale », dans Patrimoine et architecture, cahier n ${ }^{\text {os }}$ 6-7, Genève, 1999, p. 10-13.

DEUBER, G., « La cathédrale Saint-Pierre de Genève », dans Guides des monuments suisses, série 73, $\mathrm{n}^{\text {os }}$ 721-722, Berne, 2002.

HALDIMANN, M.-A., ANDRE, P., BRoIllet-RAMJOUE, E. et POUX, M., « Entre résidence indigène et domus gallo-romaine : le domaine du Parc de la Grange (GE) », dans Archéologie Suisse 24, 2001/4, p. 2-15. PRIVATI, B., « Saint-Gervais (GE): un lieu de culte, un quartier », dans Archéologie suisse 31, 2008/1, p. 2-13.

TERRIER, J., Le parking de Saint-Antoine. Découvertes archéologiques, Genève, 1996.

TERRIER, J., « Le site archéologique aménagé sous la cathédrale de Genève », dans Kunst + Architecture, Berne, 1999/4, p. 83-85.

TERRIER, J., « La gestion du patrimoine archéologique en milieu urbain, l'exemple de la Ville de Genève ", dans Restauro di manufatti architettonici allo stato di rudere. Corso di perfezionamento. Anno accademico 2001-2002, Università degli studi di Firenze, Dipartimento di Storia dell'Architettura e Restauro delle Strutture Archittoniche, Firenze, 2002, p. 122-125.

TERRIER, J., « L'intégration de l'archéologie dans la cité, la politique adoptée à Genève ", dans Quarto corso di perfezionamento in restauro di manufatti architettonici allo stato di rudere 2004-2005, 
Università degli studi di Firenze, Dipartimento di restauro e conservazione dei beni architettonici, Firenze, 2006, p. 14-17.

TERRIER, J., «L'archéologie en milieu urbain à Genève », dans Restauro Archeologico, Bollettino del Gruppo di Ricerca sul restauro archeologico, Conservazione e manutenzione di edifici allo stato di rudere, Florence, Università degli studi di Firenze, Facoltà di Archittetura, Dipartimento di restauro e conservazione dei beni architettonici, 2/2008, p. 38-42.

TERRIER, J., « L'aménagement de sites accessibles au public : un passage obligé pour l'avenir de l'archéologie genevoise ", dans Sesto corso di perfezionamento in restauro archeologico (Conservazione et manutenzione di manufatti architettonici allo stato di rudere), Università degli studi di Firenze, Facoltà di Archittetura, Dipartimento di restauro e conservazione dei beni architettonici, 2009, p. 65-72.

INDEX

Mots-clés : aménagement

Index géographique : Suisse/Genève 